\title{
Online Campus Selection Process
}

\author{
K.Parvathi1 and S.Sujitha ${ }^{2}$ Allen steve ${ }^{3}$ \\ ${ }^{1}$ Department of Computer Application,Francis Xavier Engineering college \\ ${ }^{2}$ AP.Department of Computer Application,Francis Xavier Engineering \\ college \\ ${ }^{3}$ Department of Computer Application,Francis Xavier Engineering college
}

\begin{abstract}
The Present digital and technological era has facilitated the college campus recruitment process towards a manifestation of a vibrant shift in new systems of workforce engagements. The processes like gathering and compilation of information, filing of records, and all data related administrative work are done electronically, and therefore, paperwork is considerably diminished in the new model. Significantly, very less physical campus space is utilized for interview processes, and overall, consumes minimal time as compared with more traditional recruiting methods. And the super process excellence techniques is applied in the corporate with renewed focus on quality, even people recruiting has also been structured as a online flow system for steady results.
\end{abstract}

\section{KEYWORDS}

Campus requirements, placement port, information regarding companies,

\section{INTRODUCTION}

Most of the important processes in the institutes are carried out manually such as the registration of the students, managing huge information about students, faculty members.The project is beneficial for college students, various companies visiting the campus for recruitment and even the college placement officer.It provides an easy way for the company to hire candidates and also provides the facility to candidates to apply for different jobs. This system can be used as an application for the Placement Officer of the college to manage the student information with regards to placement. This system can be used as an application to manage student information to related placement. The system handles student as well as company data and efficiently displays all this data to respective sides. This System do all work regarding placement like collecting student records, Authenticate \& activate the student profiles, Notifying eligible students via automated Email message, Check the number and percentage of placed $\&$ unplaced students. Proper login with time \& role based secured access is provided to Placement Officer, Company, College staff and students. 


\section{Architecture Diagram}

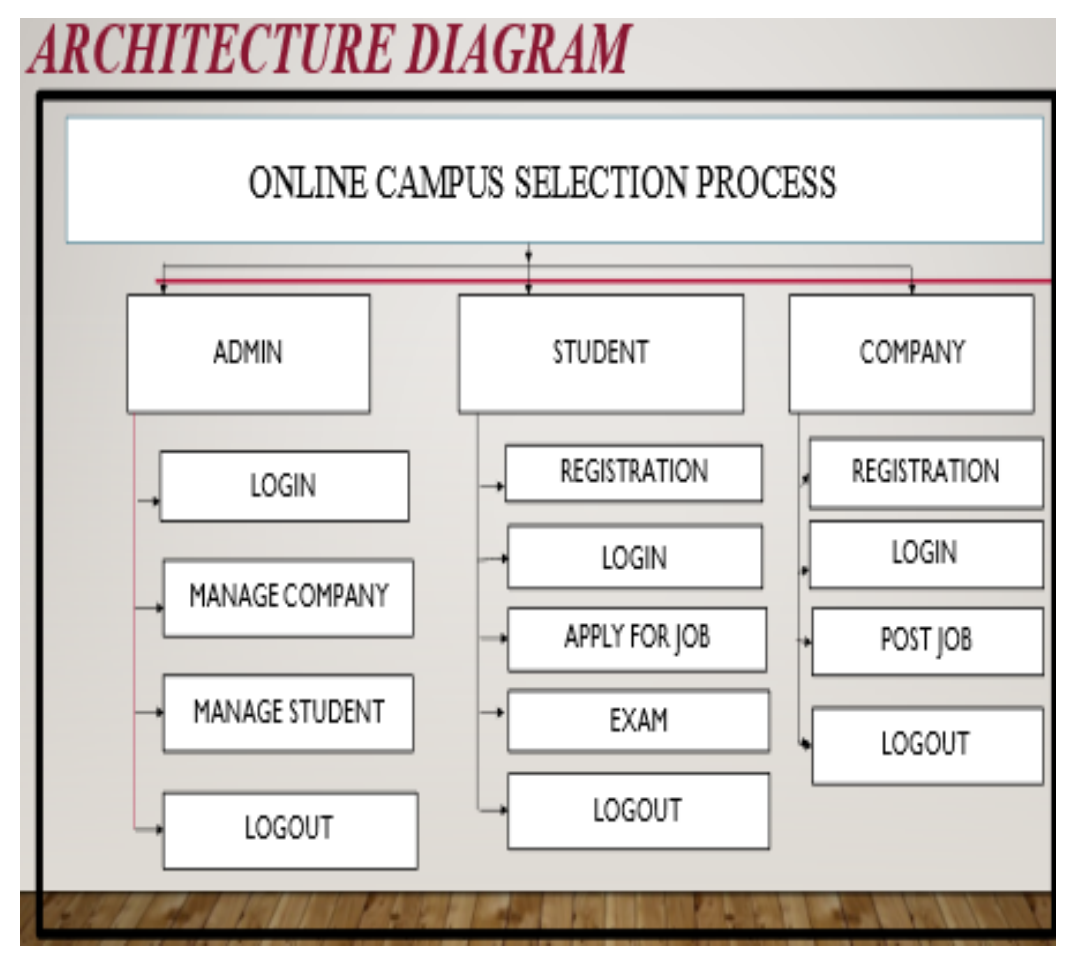

Figure 1:Architecture diagram.

\section{Problem Statements}

\section{Modules}

- Admin Module : In admin module the admin has to approve the company for to post the job details in the website.

- Student module : The Student module has to register then only he/she can attend the exam or apply for the job.

- Company module : Company module can conduct the exam those who are register as student .they can only attend the exam and apply the job. 


\section{EXPERIMENT AND RESULTS}

\section{Output screen}

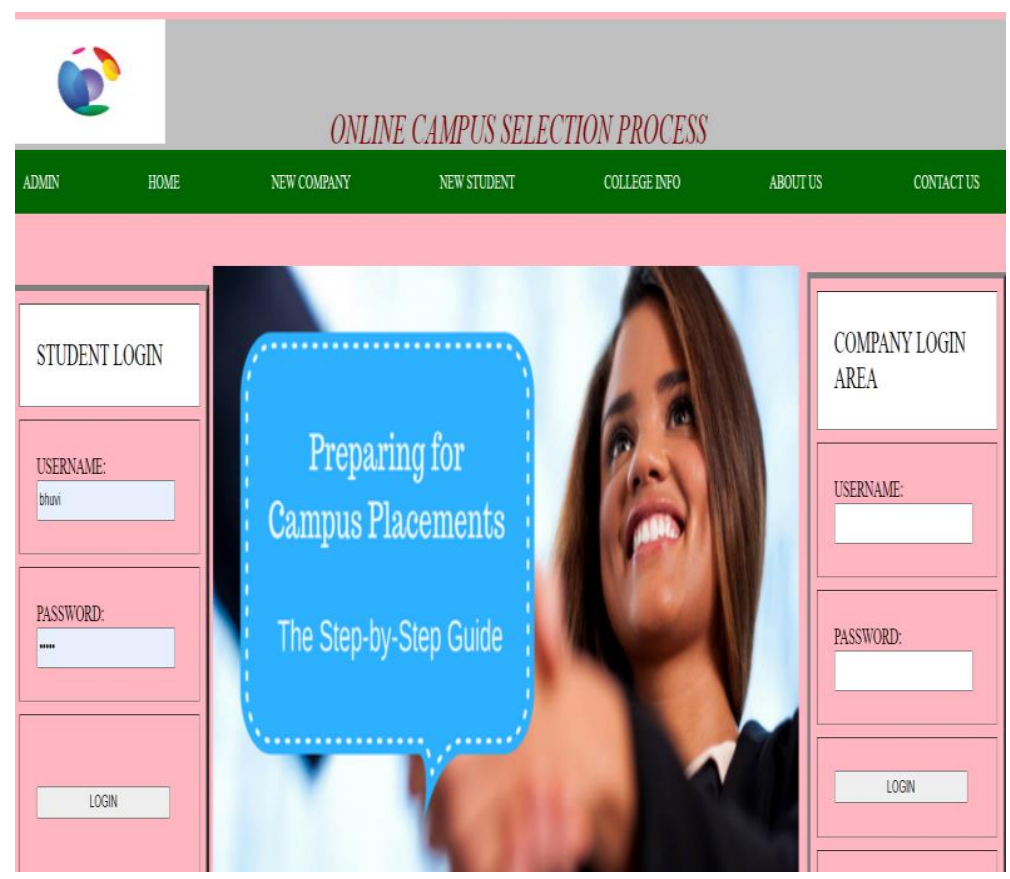

Figure 1:Login page

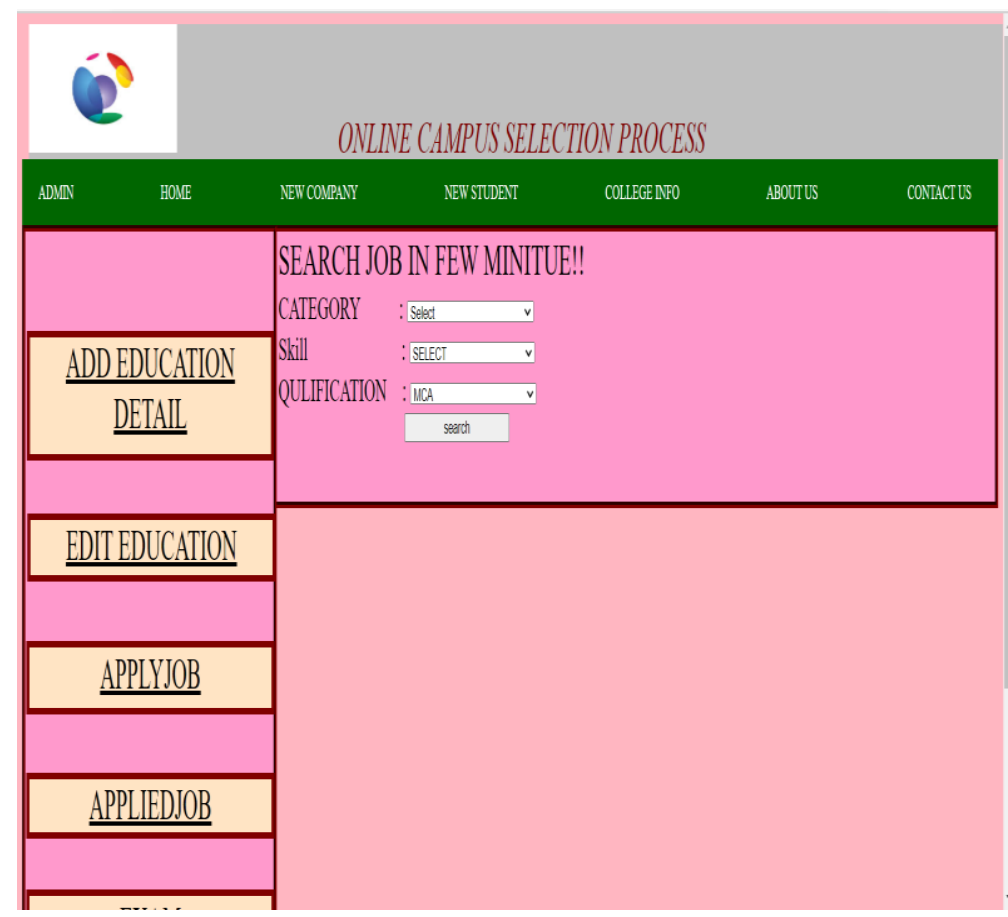

Figure 2:Job details page 


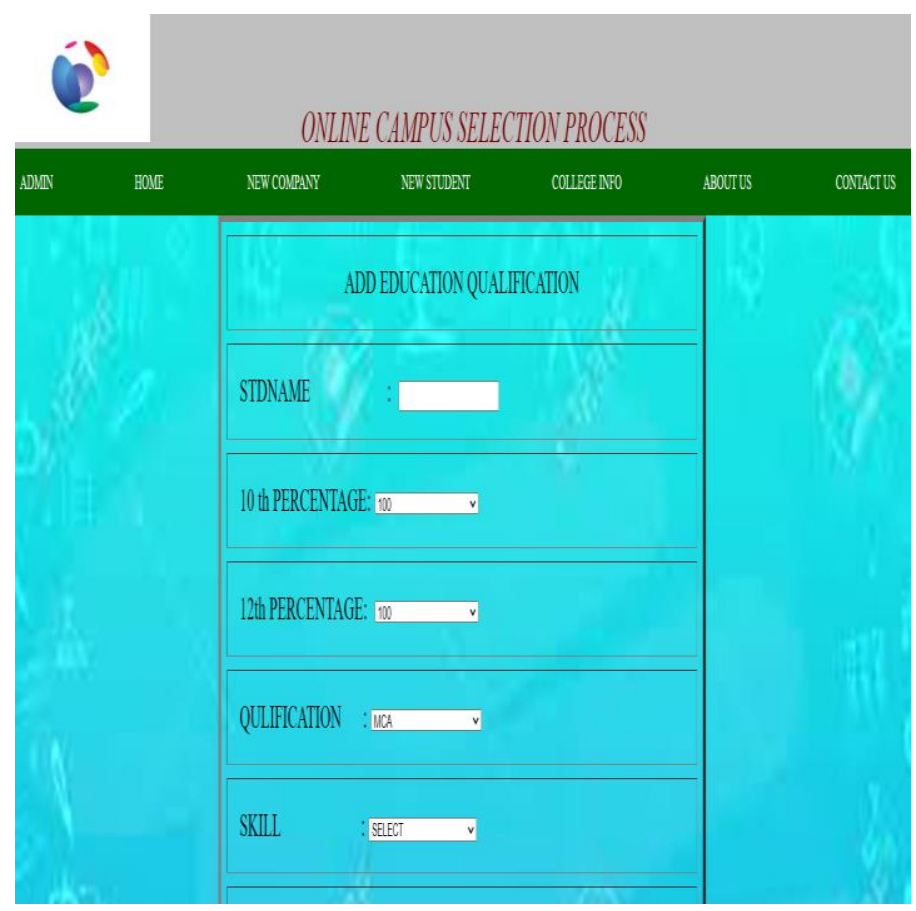

Figure 3:Educational qualification page

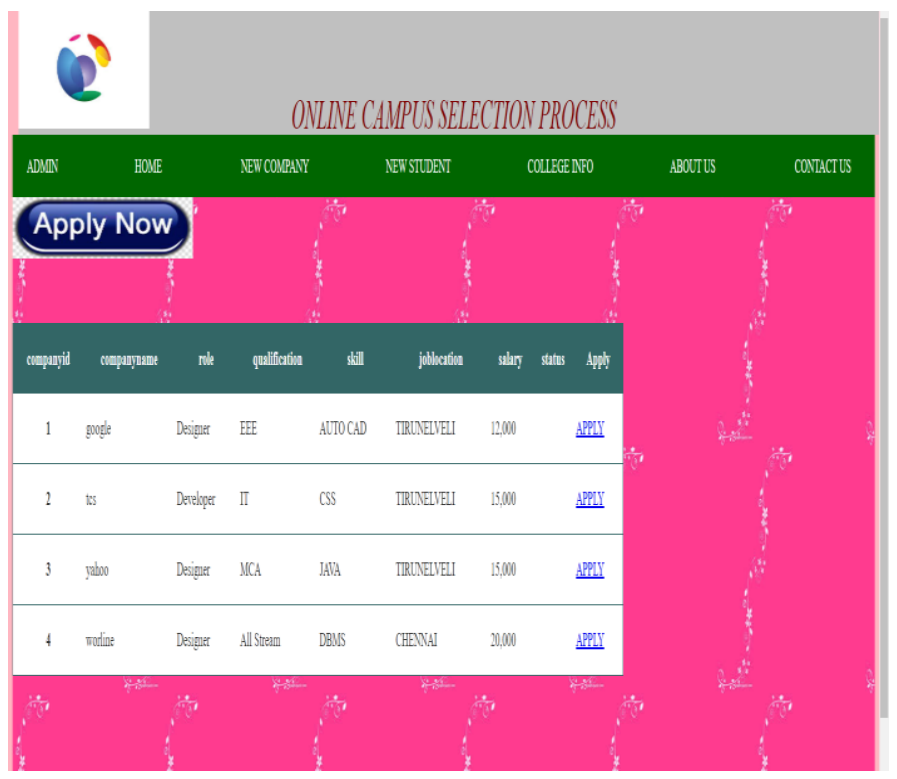

Figure 4:Apply page 


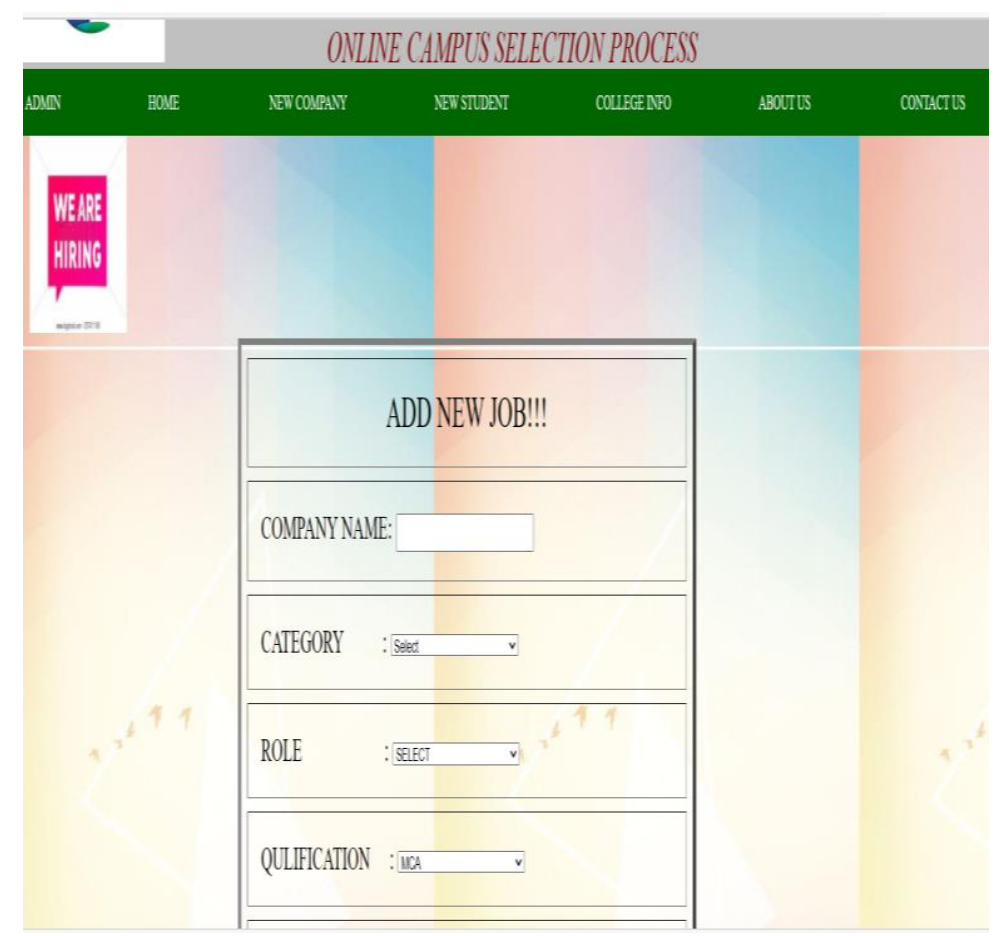

Figure 5:Add page

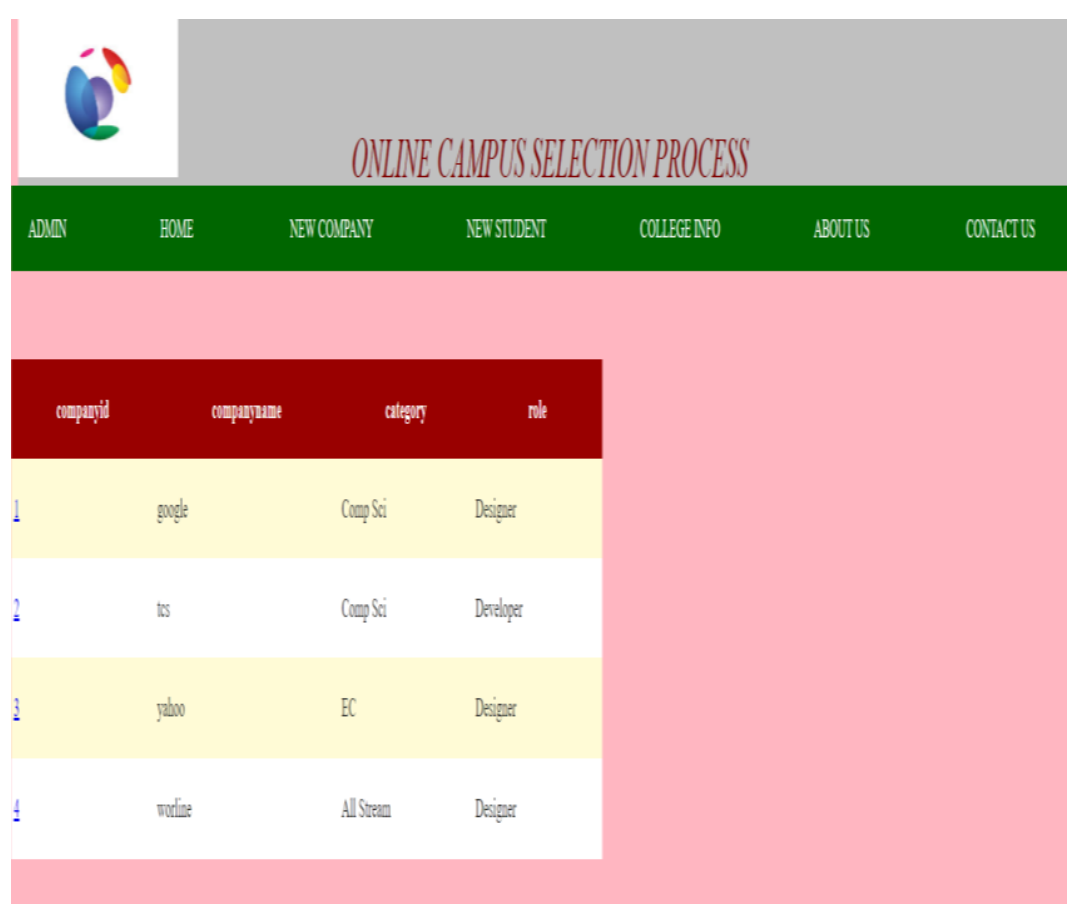

Figure 6:Out page 


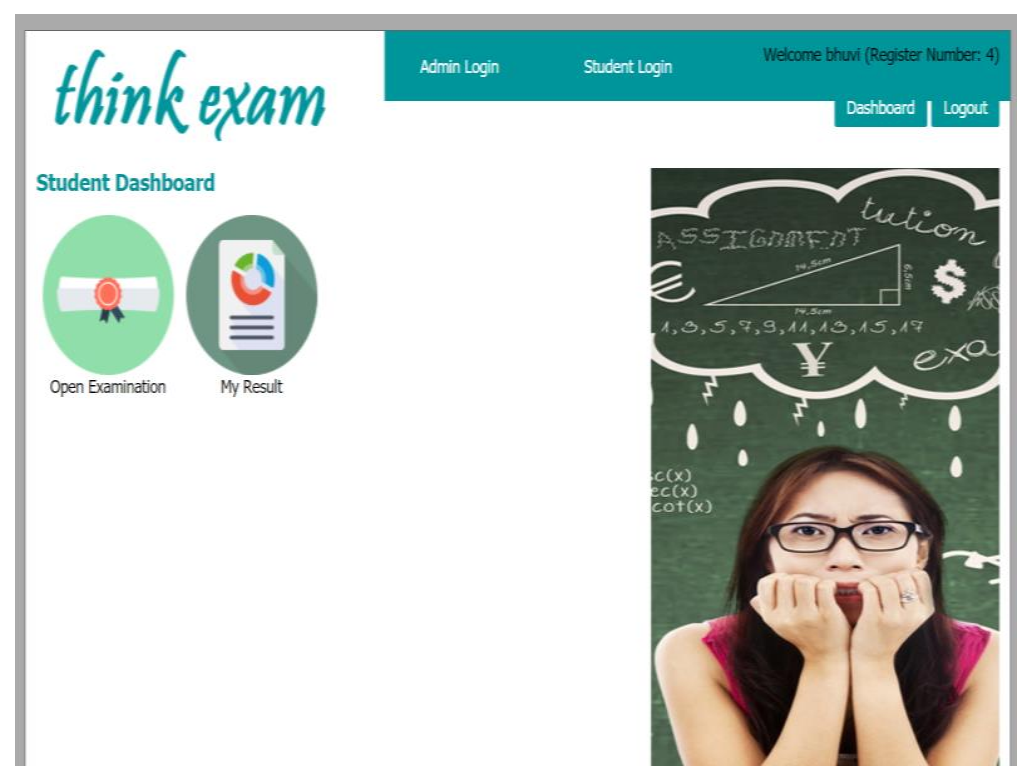

Figure 7:Admin login page

\section{Performance analysis}

The existing and proposed system are analysed,The problem identified in existing is This is the biggest challenge. If your survey is long and/or confusing you might get fake answers. Since there is less accountability, the chances for people just hitting buttons to finish are high. Check the questions you use carefully.People often take surveys because they're promised a reward at the end, resulting in them not accurately contributing to your study. Certain populations are less likely to have internet access and to respond to online questionnaires. Drawing samples is harder based on email addresses or website visitations. lack of a trained interviewer to clarify and probe can lead to less reliable data.This assumption has prevented them from automating nearly $70 \%$ Performance has been increased.

\section{CONCLuSION}

In the existing system, maximum work goes manually and it takes time for any changes in the system. This big problem is the searching, sorting and updating of the student data and no any notification method available for giving information to student except the notice board. Proposed system gets automated in the online registration all the user, activation of the user and deactivation of the user. The admin can see the user information and will validate it, generate the student list on the basis of company criteria, company details can be provided to the user.

\section{FUTURE ENHANCEMENT}

In the future we can place the system on the cloud so the maintenance of the data can be reduced.

The students get notified by the SMS or Email if he/she is got selected for the job.And we can use the system monitoring to detected the malpractice. Admin module to be developed, there by automating the services of the Admin resulting in continuous flow of records from database. 


\section{REFERENCES}

[1] NileshRathod, Seema Shah, KavitaShirsat,"An Interactive Online Training \& Placement System", International Journal of Advanced Research in Computer and Communication Engineering, Vol. 3, Issue 12,December-2013.

[2] .Mr. R. J. laird, Dr. C. R. turner mima,” Interactive Web based Placement Management - Principles and Practice using OPUS" CGU-WACE, 2008.

[3] .Hitesh Kasture, SumitSaraiyya, AbhishekMalviya, PreetiBhagat,“Training \& Placement Web Portal”, International Journal on Recent and Innovation Trends in Computing and Communication ISSN: 2321 8169 Volume: 2 Issue: 3,March-2014.

[4] .Prof. AnaghaKulkarni , PriyankaHajare, PriyankaKhandave , ShitalAdhav,SwatiPimpale,“ Implementation of Online Placement System", IJERMT All Rights Reserved International Journal of Emerging Research in Management \&Technology ISSN: 2278 -9359 (Volume-5, Issue-1), January2016.

[5] .Mr R J LAIRD,“ Interactive Web-based Placement Management-Principles and Practice using OPUS”, School of Engineering, University of Ulster, Shore Road, NEWTOWNABBEY, Co. Antrim, UK, BT37 0QB, 2008.

[6] NileshRathod, Seema Shah, KavitaShirsat,"An Interactive Online Training \& Placement System", International Journal of Advanced Research in Computer and Communication Engineering, Vol. 3, Issue 12,December-2013.

[7] Mr. R. J. laird, Dr. C. R. turner mima," Interactive Web based Placement Management - Principles and Practice using OPUS" CGU-WACE, 2008

[8] Hitesh Kasture, SumitSaraiyya, AbhishekMalviya, PreetiBhagat,“Training \& Placement Web Portal”, International Journal on Recent and Innovation Trends in Computing and Communication ISSN: 2321 8169 Volume: 2 Issue: 3,March-2014.

[9] Prof. AnaghaKulkarni , PriyankaHajare, PriyankaKhandave , ShitalAdhav,SwatiPimpale,“ Implementation of Online Placement System", IJERMT All Rights Reserved International Journal of Emerging Research in Management \&Technology ISSN: 2278 -9359 (Volume-5, Issue-1), January2016.

[10] Mr R J LAIRD,“ Interactive Web-based Placement Management-Principles and Practice using OPUS”, School of Engineering, University of Ulster, Shore Road, NEWTOWNABBEY, Co. Antrim, UK, BT37 0QB, 2008. 


\section{AuTHORS}

K.Parvathi doing final year MCA in Francis Xavier Engineering College

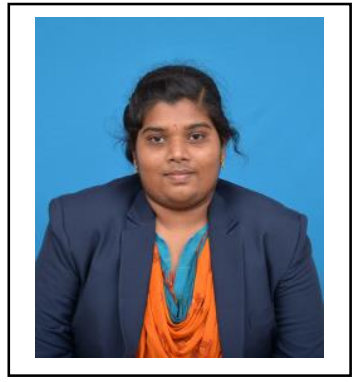

Ms. S. Sujitha working as Assistant Professor in the Department of Computer Applications, Francis Xavier Engineering College. Her area of interest is Wireless Sensor networks

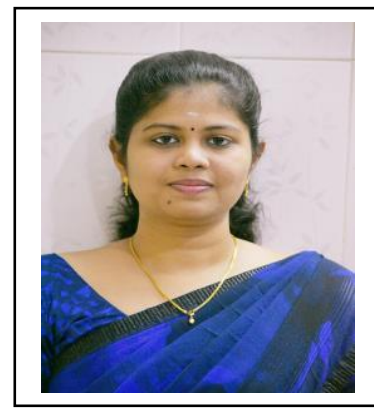

Allen Steve E doing first year MCA in Francis Xavier Engineering College

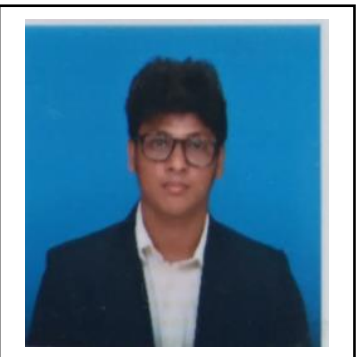

